\title{
WEB-BASED LEARNING FOR CULTURAL HERITAGE: FIRST EXPERIENCED WITH STUDENTS OF THE PRIVATE UNIVERSITY OF TECHNOLOGY IN NORTHERN TAIWAN
}

\author{
Ya-Ning Yen ${ }^{\text {a, }}$, Yun-Wu Wu ${ }^{\text {a }}$, Kuo-Hua Weng ${ }^{\text {b }}$ \\ a Associate Professor, Department of Architecture, China University of Technology, Taipei Campus: No. 56, Sec. 3, Xinglong Rd., \\ Wunshan District, Taipei City 116, Taiwan (R.O.C.) - (alexyen, davidwu@ cute.edu.tw) \\ b Assistant Professor, General Education Center, China University of Technology, Taipei Campus: No. 56, Sec. 3, Xinglong Rd., \\ Wunshan District, Taipei City 116, Taiwan (R.O.C.) - ghwong@ cute.edu.tw
}

KEY WORDS: Action research, Western Architecture History, Web-based learning

\begin{abstract}
:
E-learning assisted teaching and learning is the trend of the $21^{\text {st }}$ century and has many advantages - freedom from the constraints of time and space, hypertext and multimedia rich resources - enhancing the interaction between students and the teaching materials. The purpose of this study is to explore how rich Internet resources assisted students with the Western Architectural History course. First, we explored the Internet resources which could assist teaching and learning activities. Second, according to course objectives, we built a web-based platform which integrated the Google spreadsheets form, SIMILE widget, Wikipedia and the Google Maps and applied it to the course of Western Architectural History. Finally, action research was applied to understanding the effectiveness of this teaching/learning mode. Participants were the students of the Department of Architecture in the Private University of Technology in northern Taiwan. Results showed that students were willing to use the web-based platform to assist their learning. They found this platform to be useful in understanding the relationship between different periods of buildings. Through the view of the map mode, this platform also helped students expand their international perspective. However, we found that the information shared by students via the Internet were not completely correct. One possible reason was that students could easily acquire information on Internet but they could not determine the correctness of the information. To conclude, this study found some useful and rich resources that could be well-integrated, from which we built a web-based platform to collect information and present this information in diverse modes to stimulate students' learning motivation. We recommend that future studies should consider hiring teaching assistants in order to ease the burden on teachers, and to assist in the maintenance of information quality.
\end{abstract}

\section{INTRODUCTION}

\subsection{Motivation}

E-learning assisted learning is the trend of $21^{\text {st }}$ century and has many advantages such as freedom from the constraints of time and space, hypertext and multimedia rich resources, enhancing the interaction between learners and teaching materials. Students were passive learners when subjected to the traditional teachinglearning method. Their learning effectiveness for the absorption of knowledge were restricted. Therefore, the purpose of this study was to explore the way students can learn effectively in a web-based environment.

\subsection{Goals}

In order to organize these free resources on the Internet and use them more effectively, this study explored the resources available and organized them on an integration platform. This platform provided students with after-school learning opportunities for the course Western Architectural History in the Private University of Technology in northern Taiwan. Through the web-based platform, students could improve their motivation and learning outcomes. The main purposes of this study are as follows:

1. Explore how the web-based platform assisted students in the course of Western Architecture History.

2. Using action research to analyze the students' learning outcomes and as a reference for subsequent improvements.

\section{RELATED WORKS}

\subsection{Cultural Heritage Education}

Education and training is a fundamental task for the preservation of cultural heritage and can also enhance efforts for conserving heritage resources (S. Elwazani, 2005). In 2003, ICCROM (International Centre for the study of the Preservation and Conservation of Cultural Property) had promoted the International Advanced Course titled Architectural Records, Inventories and Information System for Conservation. A. Almagro Vidal \& A. Almagro shared the experiences of ARIS and CLADIC courses. These courses trained local professionals in the whole process of documentation with simple, easy and low/medium-cost systems. This study also pointed out that many inexperienced institutions co-operated with teams from developing countries with expensive and sophisticated tools that had carried out many wonderful recording projects, but these tools were unavailable for such countries in the future (AlmagroVidal \& Almagro, 2005).

In Taiwan, the government puts emphasis on the preservation of cultural assets and actively promotes the application for World Heritage. Educational institutions and research centers established a number of related courses to educate students and practitioners. However, students in Taiwan generally lacks in the international perspective, not to mention the concept of world heritage preservation. Therefore, the way to enhance students' world heritage concepts and international outlook in a simple, easy, and affordable way became an important issue. 


\subsection{E-learning}

E-learning refers to the use of various kinds of electronic media, information, and communication technologies (ICT) in education. E-learning may be termed technology-enhanced learning (TEL), computer-based training (CBT), Internet-based training (IBT), web-based training (WBT), online education, virtual education or digital educational collaboration depending on whether a particular aspect, component or delivery method is given emphasis ("E-learning," 2013).

According to the ASTD [American Society for Training and Development], e-learning is an entire application process of using computerized, networked, virtual classrooms and digital technology in teaching and learning activities. ASTD gave the definition of e-leaning as a mode of implementing teaching through the Internet electronic information technologies in order to achieve teaching objectives, including: e-learning, Web-based learning and distance learning ("Understanding E-Learning 2.0," n.d.). To quote Garrison \& Anderson, "e-learning is an open system. With the power of the Internet, the teaching and learning transaction is exposed to unfathomable amounts of information" (Garrison, 2011). This study will explore the implementation of e-learning in traditional teaching activities, and to explore how this mode affects teaching and learning outcomes.

\subsection{Western Architectural History}

The goals of Western Architecture History, as a basic course, was to set emphasis on the building of basic spatial patterns, detailed features, as well as its social impact. This course tried to make students realize the basic architectural history and theory. On the other hand, it enabled students to produce individual architectural culture appreciations. There were four professional goals:

1. Overall concepts of architecture.

2. Understand the progress of western architecture.

3. Cumulative spatial design elements and vocabulary.

4. Promoting the connotation of modern architectural designs.

This course put emphasis on the factors affecting each progressive architectural period, so the relationship of time and location between different periods was very important. Table 1 shows the periods of western architecture.

\begin{tabular}{|c|c|c|}
\hline No & Period & Start - End \\
\hline 1 & Mesopotamia Architecture & BC3000 BC323 \\
\hline 2 & Egypt Architecture & BC3000 BC30 \\
\hline 3 & Greece Architecture & BC3000 BC146 \\
\hline 4 & Rome Architecture & BC750 AD476 \\
\hline 5 & Early Christianity Architecture & AD323 AD326 \\
\hline 6 & Byzantine Architecture & AD323 AD1453 \\
\hline 7 & Romanesque Architecture & $8 \sim 12$ Century \\
\hline 8 & Gothic Architecture & $12 \sim 15$ Century \\
\hline 9 & Renaissance Architecture & $15 \sim 16$ Century \\
\hline 10 & Baroque Architecture & 15 Century $~$ \\
\hline 11 & Rococo Architecture & 15 Century $~$ \\
\hline & Table 1. Western Architecture progress period \\
\hline
\end{tabular}

\subsection{Action Research}

In the 1930s, American social psychologist Lewin proposed the "action research method" (action research). Action research is a method which combines action and research. Based on practical problem solving, researchers work with experts and academics to develop problems into research topics, as well to conduct systematic research for pragmatic problem solving. Because action research is very suitable for studying and solving problems in actual teaching environments, this study will use the action research method to investigate students' learning outcome in the digital environment. The learning situations are reflective and interactive, in order to adjust the design of teaching activities and mentoring strategy.

\subsection{Summary}

Education and training is a fundamental task for the preservation of cultural heritage and can also enhance efforts for conserving heritage resources. With the potential of the Internet, teaching and learning activities has many possibilities. The course Western Architectural History puts emphasis on the factors affecting each progressive architectural period, so it is important to understand the relationship between time and location of heritage among different periods. The purpose of this study is to explore how rich Internet resources can assist students in the Western Architectural History course.

\section{PROCEDURE}

\subsection{Framework}

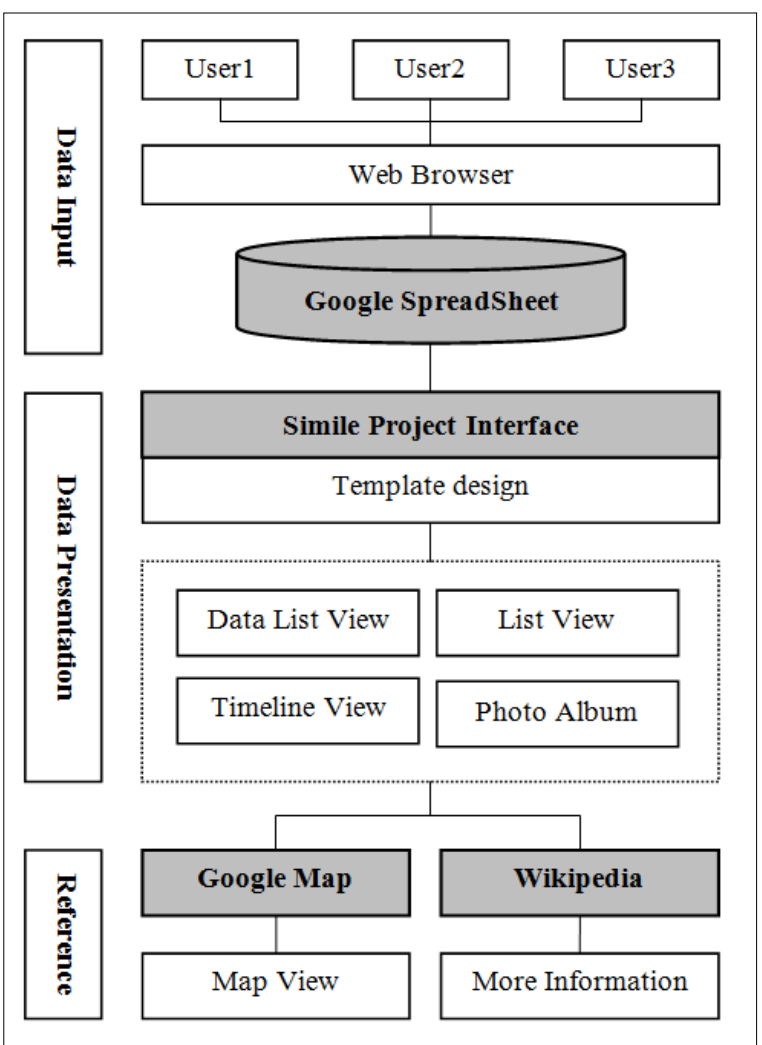

Figure 1. Procedure of information collection and presentation

\subsection{Participants}

The participants were 50 students of the Private University of Technology in northern Taiwan. All participants were free to choose whether to participate in the learning activities. 


\subsection{Tools}

3.3.1 SIMILE Widget: The SIMILE widget is an opensource "spin-off" from the SIMILE (SEMANTIC INTEROPERABILITY OF METADATA AND INFORMATION IN UNLIKE ENVIRONMENTS) project at MIT. The SIMILE was focused on developing an open source too that empowers users to access, manage, visualize and reuse digital assets. Among these widgets, Exhibit is designed especially for large-scale datarich interactive web pages and lets developers easily create web pages with advanced text search and filtering functionalities, with interactive maps, timelines, and other visualizations. Using the SIMILE widget effectively can reduce the development time for web page developers. Since the characteristic of diverse views to represent information, the SIMILE could meet the demands of students with different learning styles.

3.3.2 Google Spreadsheets: Google spreadsheets is a popular applications from Google, which is an online collaborative spreadsheet application. Users can access this system via any internet browser to share data via the Internet through the invitation of people to collaborative editing. Google spreadsheets are also easily accessible to users with mobile devices. Google spreadsheets can be published as an online form system, such as questionnaires, to collect data through the Internet. In recent years, Google spreadsheets also become one of the main tools for researchers to collect data via the Internet. Data collected with Google spreadsheets can also be shared with other applications. In this study, we would use this system to collect data from participants via the Internet.

3.3.3 Wikipedia: Wikipedia is an openly editable multilingual, web-based, free-content encyclopaedia project, operated by the Wikimedia Foundation. "Wikipedia" is a portmanteau of the words wiki (a technology for creating collaborative websites, from the Hawaiian word wiki, meaning "quick") and encyclopaedia. It is written by mostly anonymous Internet volunteers. Anyone with Internet access can write and make changes to Wikipedia articles. Updated to 02:40, 29 March 2013, Chinese Wikipedia right now has 682,475 content articles and 2,897,281 pages in total. There have been 26,948,650 edits, 33,090 uploaded files, and 1,399,230 registered users ("Wikipedia: About", n.d.). Since Wikipedia is written, edited, and reviewed collaboratively by public volunteers, information on Wikipedia has higher accuracy than numerous other information on the Internet. Using information on Wikipedia to assist teaching/learning activities can avoid blind searching on the Internet and save time for the students.

3.3.4 Google Maps: Google Maps is a map service that can be viewed in any web browser. You can view basic or custom maps and local business information. By clicking and dragging, you can view adjacent areas immediately. You are able to view satellite images of your desired location, and you can zoom and pan. You can use Google Maps one of several ways. If you know the exact latitude and longitude coordinates of a location, you can type them into the search bar and click the "Search" button (or press Enter). Search results appear in the left panel of the page and as icons on the map itself. Google Maps can give us more context information than pure textual information ("Welcome to Google Maps - Maps Help," n.d.). With the visual aids of Google Maps assisting the course Western Architecture History, students can better understand the relationship of locations among buildings.
3.3.5 Data Collection: The procedure of data collection is explained as fellows: first, the researchers classified the building types from the textbook as the basis for the Google spreadsheet form. Second, researchers built an integration platform composed with the Google spreadsheet online form, SIMILE widget, Wikimedia and Google Maps as participatory learning information gathering tool. This form gathered some useful information including students' ID, building's name, country, construction era, completion date, type of construction, latitude and longitude, brief information and photos from Wikipedia. All the students who participated in this class could join this learning activity voluntarily. This platform was opened for all students who attended this course, and students could see others' efforts freely. In the front-end, students gathered data and imported them to the platform. In the back-end, teachers checked the correctness of the data format.

\subsection{Platform Design}

This web-based platform was developed to assist the course of Western Architecture History. Figure 2-8 presented some screen snapshots of this platform.

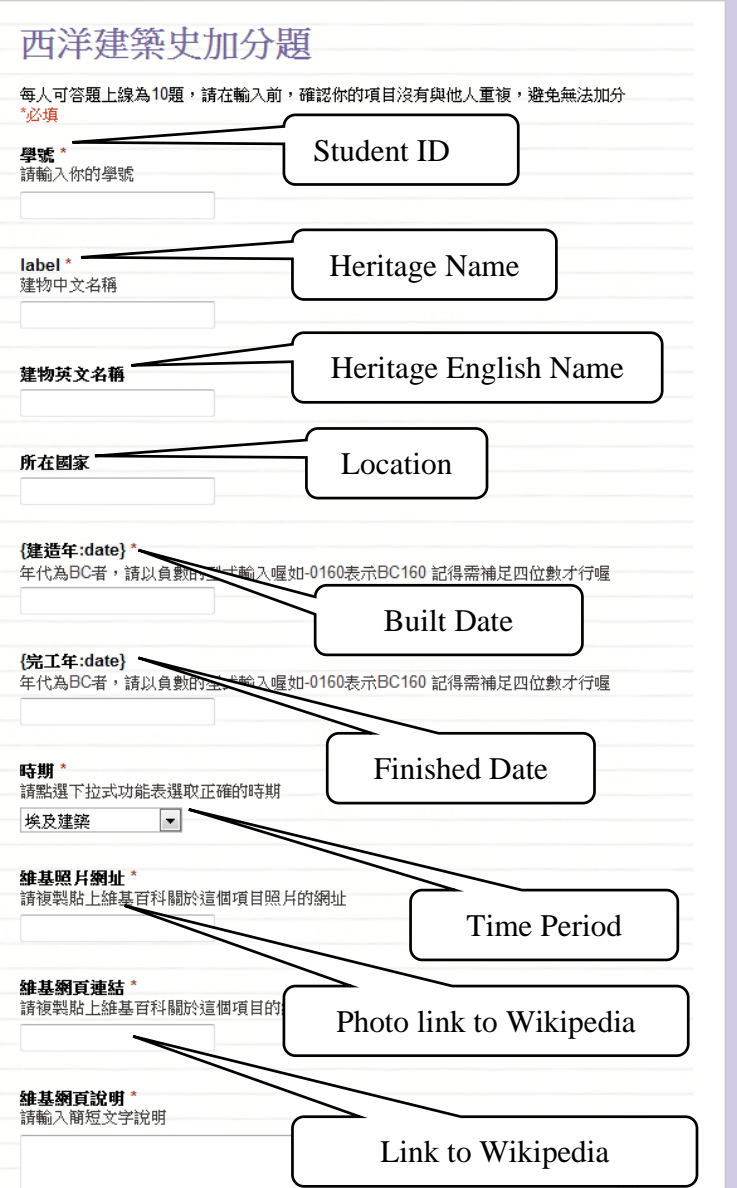

Figure 2. Google spreadsheets online form design 


\begin{tabular}{|c|c|c|c|c|c|c|}
\hline & A & B & c & D & E & \\
\hline 1 & 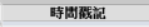 & 學梀 & label & 建物莫文名桶 & 所在国家 & 健造年: \\
\hline 2 & $2010 / 5 / 16$ 下午 2.08 .04 & 9811446047 & 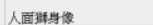 & Sphinx & 堙及 & .2500 \\
\hline 3 & $201015 / 19$ 上年 12.43 .54 & 49811446012 & 凡沬看宫 & 法諳 : Chateau de Versailles & 法图 & 1624 \\
\hline 4 & & & & & & \\
\hline & $201015 / 27$ 下午 $2.47: 56$ & 9811446077 & 大本垟 & Big Ben & 英圈 & 1850 \\
\hline 5 & $2010 / 5 / 29$ 下午 $3 \cdot 18.15$ & 5) 9811446018 & 巴比倫空中花图 & Hanging Gardens of Babylon) & 伊拉克 & 0604 \\
\hline 6 & 201015120 下午 8.01 .35 & 9811446006 & 巴釷市政店 & Hốtel de Ville & 法图 & 1502 \\
\hline 7 & $2010 / 5 / 17$ 下午 2.08 .49 & 9711446053 & 巴笋型然院大敖堂 & Notre Dame de Paris & 法困 & 1163 \\
\hline 8 & $201015 / 26$ 下午 $8: 39.01$ & 9811446045 & 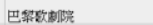 & Paris, Banks of the Seine & 法圆 & 1862 \\
\hline 9 & 201015/20 下午 $11: 56 \cdot 31$ & 1 9811446115 & 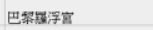 & THE LOUVRE PARIS & 巴策 & 1546 \\
\hline 10 & $201015 / 27$ 上午 4.27 .30 & 9811446057 & 比腾主耕座堂 & Duomo di Santa Maria Assunta & 大利 & 1063 \\
\hline 11 & $2010 / 5 / 16$ 下午 $3 \cdot 19 \cdot 14$ & 9811446047 & 比期䆖措 & Piazza del Duomo, Pisa & 和利 & 1173 \\
\hline 12 & 2010/5/18 下午 $11: 50: 31$ & 1) 9712446067 & 卡夫拉金字塔 & Pyramid of Khatre & 埃及 & .2558 \\
\hline 13 & $2010 / 5 / 19$ 上午 1232.36 & 39811446012 & 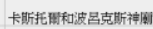 & & 大利 & .0495 \\
\hline 14 & 201015/29 下午 11.12 .22 & 29811446121 & 四景聖軩䄈堂 & San Carlino & 利 & \\
\hline 15 & 201015/27 下午 4.32 .52 & 9711446053 & 尼楛拉城門 & Ponta Nigra & 德图 & 0180 \\
\hline 16 & & & & & & \\
\hline & & 981144 & & Pyramid of Djoser & 境及 & .2630 \\
\hline
\end{tabular}

Figure 3. Google spreadsheets

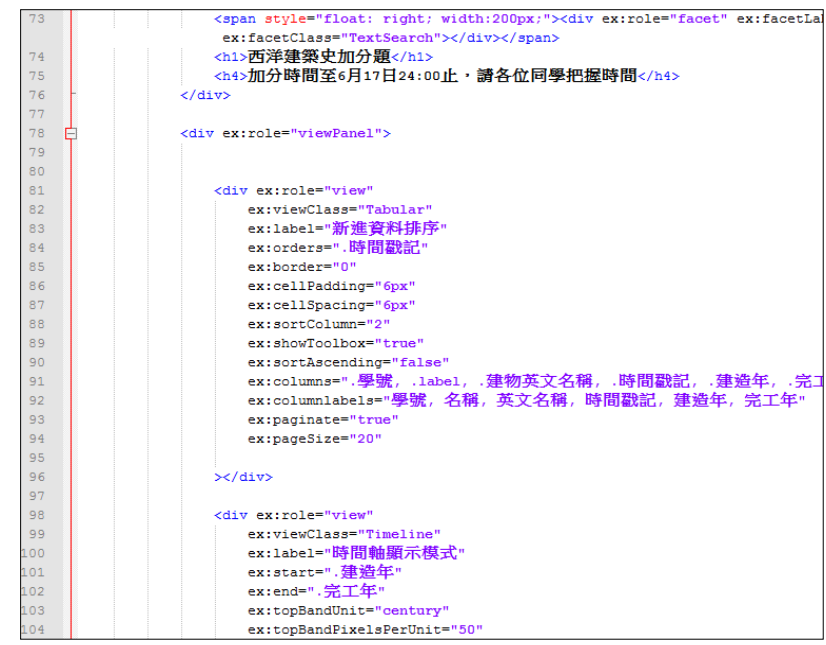

Figure 4. Web page layout design

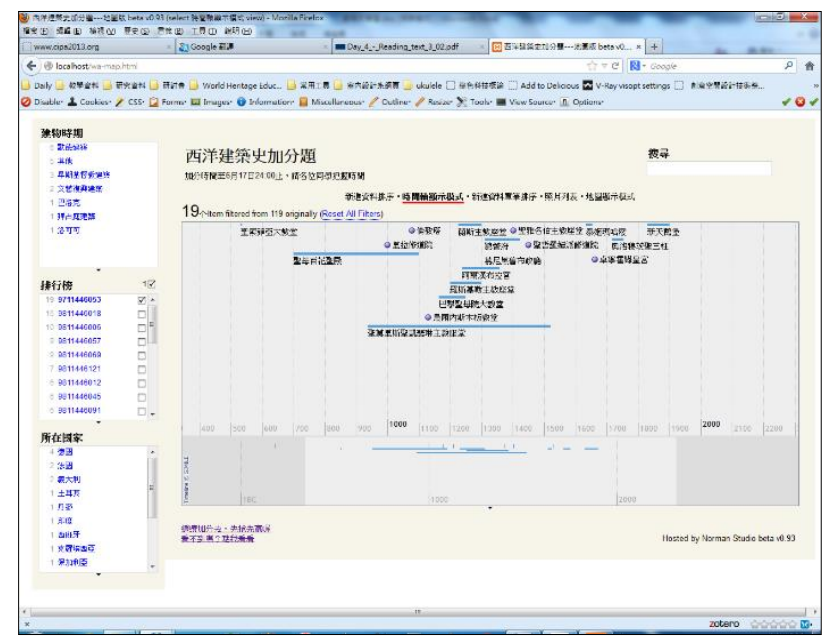

Figure 5. Timeline mode view

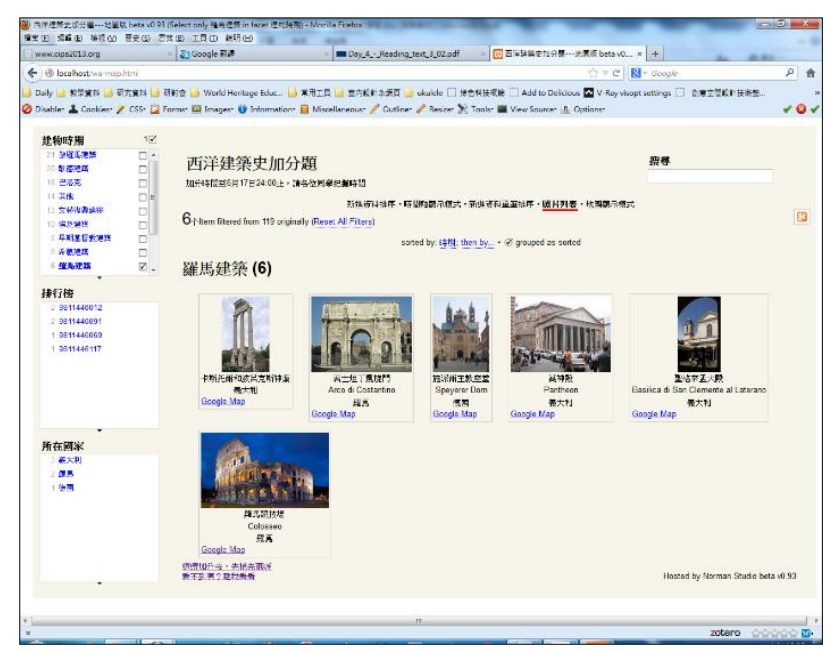

Figure 6. Photo list mode view

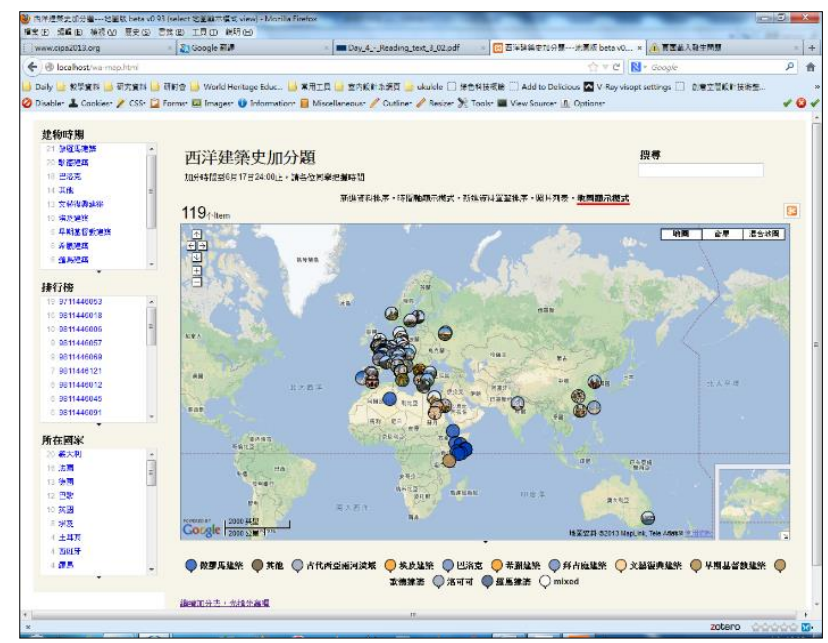

Figure 7. Map mode View

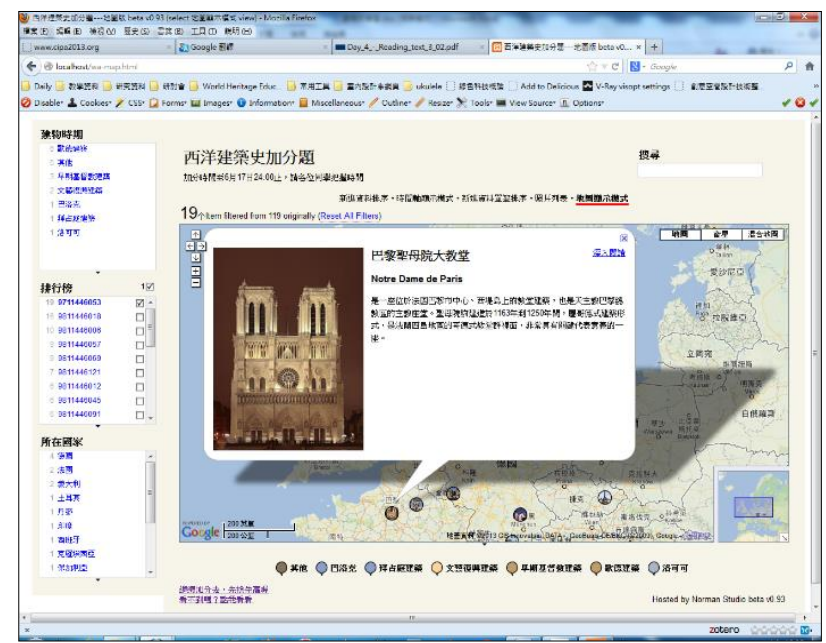

Figure 8. Popup window in map mode 


\section{FINDINGS}

\subsection{Data Collection from Google spreadsheets}

The collected data was analysed at the end of the semester, a total of 17 students posted 118 distinct data. Every student posted 6.94 data in average. Top 3 building type were Romanesque ( 21 posts, $17.80 \%)$, Gothic $(20,16.95 \%)$, Baroque (17, 14.41\%) (Fig. 9). In addition, after analysed the type of buildings posted by the participants, we found the students had different preferred building types. From Fig. 10, we found the average number of building type was 3.96 , which also shows that these posts concentrated in on preferred building types (Fig. 9). Through interviews with participants, the main cause was that these three building types had become a perfect form in architecture history and data of these cases were more easily collected through the internet. In Fig. 10, we found most of participants posted at least 5 cases which revealed that participants were willing to spend their time to post the cases they collected and shared with others. Also, by viewing data in the map mode, cases posted by participants were presented in a way that other participants would be able to understand the relationship between the locations of different types of buildings (Fig. 11).

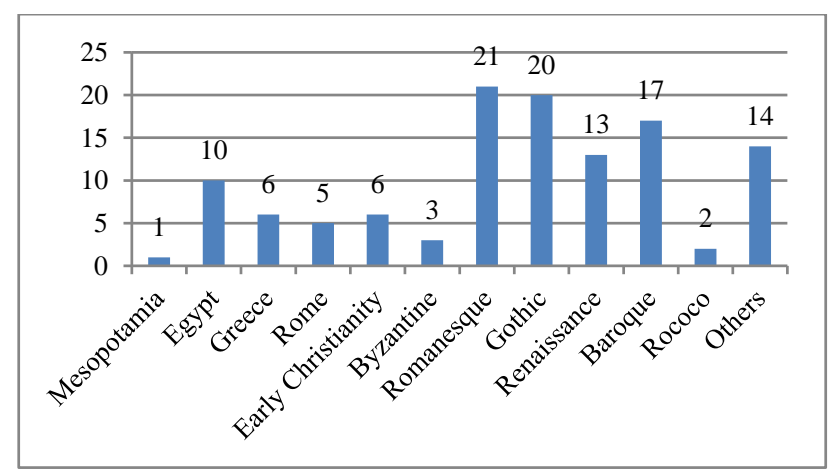

Figure 9. Building type and amount

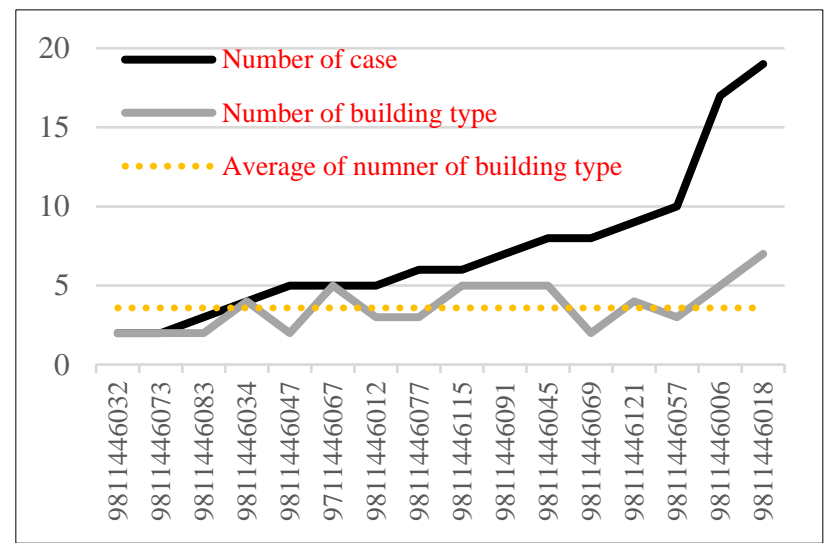

Figure 10. Building type and amount data shared by participants

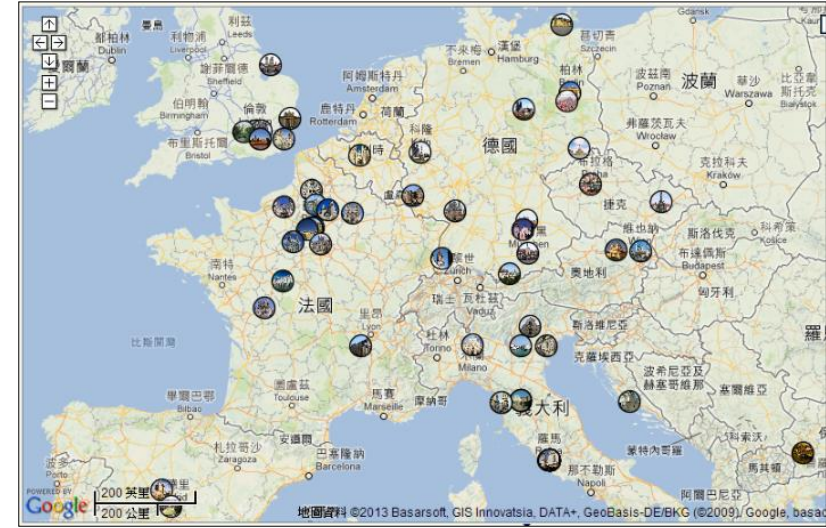

Figure 11. Map mode view showed data scattered

\subsection{Action Research}

Selected interviews from students who participated in the study:

Student1: After this class, I learned that what did this building had happened from past to the present. With this online learning system, I had learned more than I used to do. This system was like a database that was maintained by every student. Everyone could share the information found on Internet. Through this platform, I could find something interesting, such as architecture and countries, that I had never minded. Moreover, I could read more information from Internet and that information was well-organized. The only action for me to do was to click then I got more useful information. Since this platform had linked to the Google Maps, so it let us understand the actual location of the building, as well as the classification of different styles. The timeline mode also stimulated me to memorize construction period of the building in different way. This platform could save my time on searching the web and through well-integrated information could make my learning more effectively.

Student2: In the past, it was not easy to integrate database with various data types. In this platform, information posted by participants were well-organized through Internet. Information were no longer scattered in various sites or books. In the past, it was hard to figure out the relationship among these buildings for students. This platform provided a timeline mode to present all the building information and made it clearly for us to understand relationship between these buildings. The Google Maps mode also showed the location. All the information from the Internet, such as Google Maps, Wikipedia, could ensure that the real-time data updates. I thought, with this platform, it was very useful for everyone in learning the course of "Western Architecture History". I hope this platform to integrate East and West relations and the introduction of the time of the building in the future. 


\subsection{DISCUSSION}

Results revealed that a total of 17 students posted 118 distinct data. There were some incorrect or incomplete data. We supposed possible reasons are as follows:

4.3.1 Students lacking in the dialectical ability: In Taiwan, infrastructures of the Internet are very general and people can easily access the Internet with mobile devices and notebook computers. People can search for the required information to complete their daily homework. The Internet has become one of the essential tools for most students. Although students were willing to search for data on Internet, they lacked dialectical ability to think deeply and to identify the correctness of these numerous sources of information. In the age of information explosion, filtering the huge amount of data to find meaningful and useful information in the network is an important issue.

4.3.2 The importance of teaching assistants: In this study, we had encountered limitations in terms of manpower. All of the required works for this research had been done by our research team without any assistants. However, there were still timeconsuming teachers' works waiting for us, none the less. Therefore, we did not have enough time to regularly check the correctness and completeness of the data posted by the participants. After an initial review, we found that the major errors are incorrectness of building positioning, which might be input error.

4.3.3 Web-based teaching and learning is the trend of the future: Students were passive learners in traditional mode of teaching and learning. The main source of knowledge that students learned from were restricted to classrooms. In the $21^{\text {st }}$ Century, people use the Internet in every field to assist their daily work. Since there is a wealth of information on the Internet, students could easily access them from the Internet with their mobile devices and notebook computers. As a teacher, we should think seriously about the changes that are already happening in the education field, and what teachers should do to keep our teaching methods relevant to the current world. We should not only change our traditional teaching methods and learning activities, but we should also change our perspectives.

\section{CONCLUSION}

The main purpose of this study was to develop a web-based learning environment for students, reflective of modern developments in heritage conservation. The trend of heritage conservation had changed from substance conservation into virtual representation. The main purpose of representation is education. The contribution of this study aims to establish a practical learning platform to cultivate students in developing concepts relevant to heritage conservation. This study also used action research to explore the students' satisfaction regarding the platform.

The main resources used in the study are the Google spreadsheets form, SIMILE widget, Wikipedia and Google Maps. The participants were 50 students of the Private University of Technology in northern Taiwan. The collected data was analysed at the end of the semester, a total of 17 students posted 118 distinct data. Every student posted 6.94 data in average. Participants were willing to search for buildings of different periods. Action Research showed that student's acceptance for this platform were very high. Participants felt interested in this platform, because it could not only present information in timeline mode, map mode, but also could provide more information from the Internet. Participants were willing to participate in similar teaching/learning activities in the future. We recommend that hiring teaching assistants is necessary, because teaching assistants can ease the burden on teachers and help researcher check the correctness of the information posted by participants.

In further studies, we aim to get more students as participants and use technology accept mode (TAM) to explore attitudes regarding the platform.

\section{REFERENCES}

Almagro-Vidal, A., Almagro, A. (2005). Training on Documentation in Architectural Heritage: The Experience of ARIS and CLADIC Courses. CIPA 20th International Symposium.

Garrison, D. R. (2011). E-learning in the 21st century. Taylor \& Francis, pp. 53.

S. Elwazani (2005). Heritage documentation education: an international collaborative account. CIPA 20th Inter-national Symposium.

E-learning. (2013, March 27). In Wikipedia, the free encyclopaedia. Retrieved from http://en.wikipedia-.org/w/index.php?title=E-earning\&oldid $=547189467$

Understanding E-Learning 2.0. Retrieved March 27, 2013, from http://www.astd.org/Publications/Newsletters/Learning-

Circuits/Learning-Circuits-Archives/2007/07/-Understanding-ELearning-20

Welcome to Google Maps - Maps Help. Retrieved March 29, 2013, from http://support.google.com/maps/bin/answer.py?hl=en\&topic $=1687350$ \&answer $=144352$

Wikipedia:About. (2013, March 30). In Wikipedia, the free encyclopedia. Retrieved from http://en.wikipedia.org/w/index.php?title=Wikipedia:About\&oldid=546589577

Revised July 2013 